
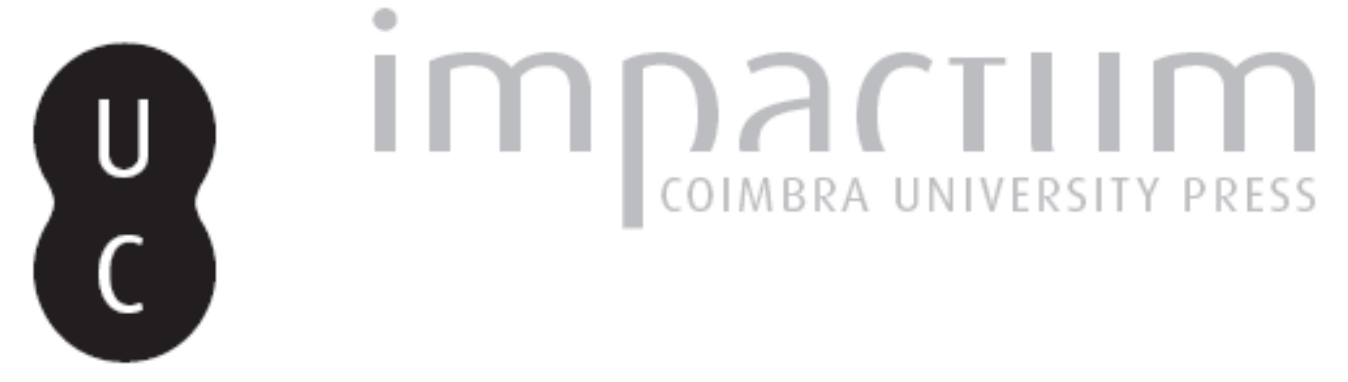

\title{
Corpo, imagem, objeto: a cadeira LC9 e Charlotte Perriand
}

\author{
Autor(es): Rubino, Silvana
}

Publicado por: Editorial do Departamento de Arquitectura

URL persistente:

URI:http://hdl.handle.net/10316.2/37203

DOI:

DOI:http://dx.doi.org/10.14195/1647-8681_1_2

Accessed : $\quad$ 26-Apr-2023 14:42:16

A navegação consulta e descarregamento dos títulos inseridos nas Bibliotecas Digitais UC Digitalis, UC Pombalina e UC Impactum, pressupõem a aceitação plena e sem reservas dos Termos e Condições de Uso destas Bibliotecas Digitais, disponíveis em https://digitalis.uc.pt/pt-pt/termos.

Conforme exposto nos referidos Termos e Condições de Uso, o descarregamento de títulos de acesso restrito requer uma licença válida de autorização devendo o utilizador aceder ao(s) documento(s) a partir de um endereço de IP da instituição detentora da supramencionada licença.

Ao utilizador é apenas permitido o descarregamento para uso pessoal, pelo que o emprego do(s) título(s) descarregado(s) para outro fim, designadamente comercial, carece de autorização do respetivo autor ou editor da obra.

Na medida em que todas as obras da UC Digitalis se encontram protegidas pelo Código do Direito de Autor e Direitos Conexos e demais legislação aplicável, toda a cópia, parcial ou total, deste documento, nos casos em que é legalmente admitida, deverá conter ou fazer-se acompanhar por este aviso.

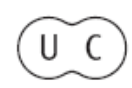




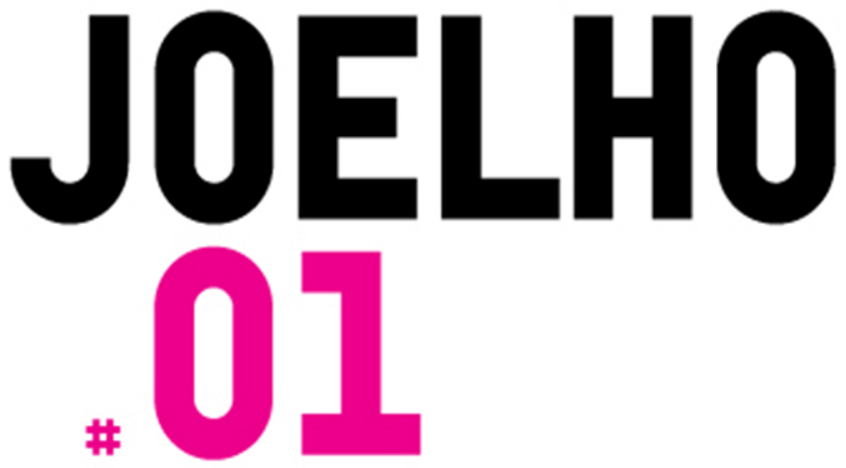

\section{MULHERES NA ARQUITECTURA}

Jorge Figueira

Coordenação

Silvana Rubino

Carla Lopes

Liliana Carvalho

Joana Bem-Haja

Filipa Cabrita

Inês Antunes

Telma Silva

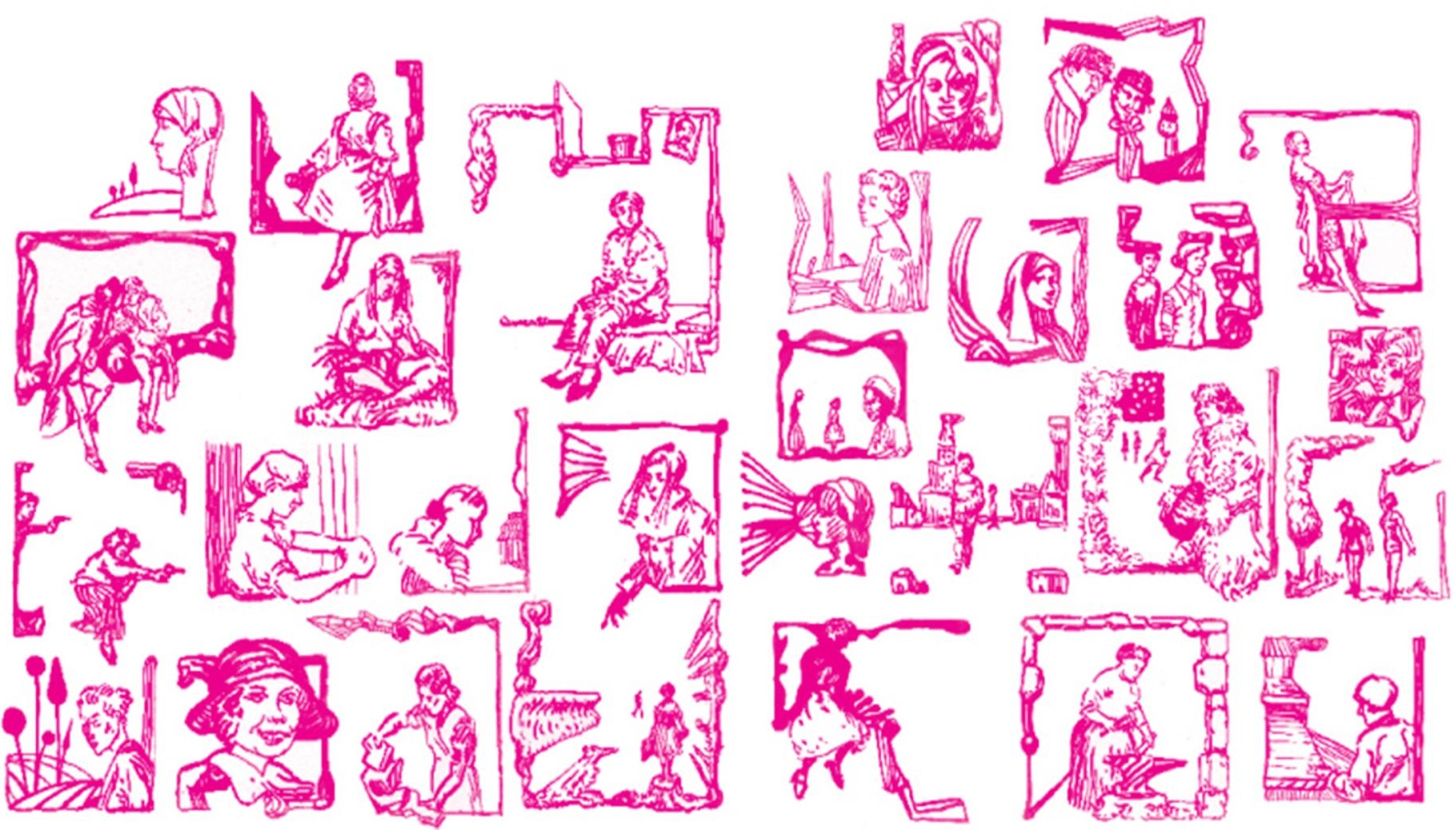




\section{Corpo, Imagem, Objeto: A cadeira LC9 e Charlotte Perriand}

Silvana Rubino

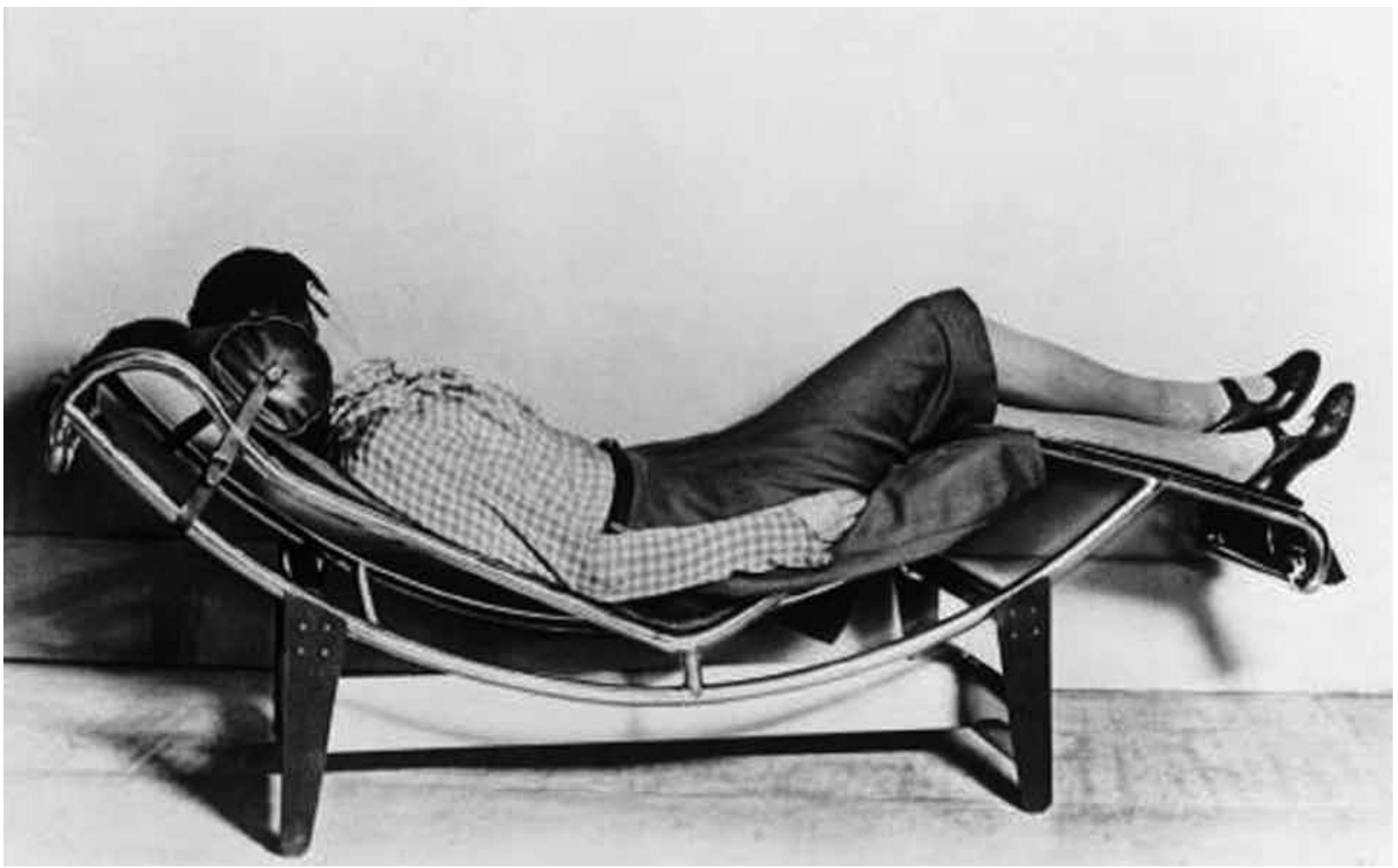




\section{APRESENTAÇÃO}

Em livro de 1996, a arquiteta, crítica e feminista Beatriz Colomina observou que a maioria dos edifícios projetados e construídos por Le Corbusier são fotografados sem mostrar pessoas - o que no limite, observemos, significa mostrá-los sem uso - e que nas poucas exceções vemos mulheres que parecem evitar a câmara: estão comumente distantes ou de costas. A autora cita como exemplo mais eloqüente dessa condição uma foto realizada no Salon d'Automne de 1929 em Paris, que mostra um ambiente criado por Le Corbusier em parceria com a jovem designer Charlotte Perriand lembrando que parte dos móveis ali exibidos ela já havia concebido e mostrado antes de começar a trabalhar com o conhecido arquiteto, e que o nome de Perriand foi desde então eclipsado de sua autoria.

In this image, which Le Corbusier published in the Oeuvre complete, Perriand herself is lying on the chaise-longue, her head turned away from the camera. More significant, in the original photograph employed in this photocollage (as well as in another photograph in the Oeuvre complete that shows the chaise-longue in the horizontal position),

I Beatriz Colomina fez parte da publicação coletiva Assemblage, que buscou situar-se numa certa contramão em meio a outros periódicos de arquitetura, numa postura autodenominada pós-crítica. one can see that the chair has been placed right against the wall. Remarkably, she is facing the wall. She sees nothing. (COLOMINA, 2000 [1996]: 269) ${ }^{1}$

A personagem analisada, já no final de sua vida e ainda em plena atividade, teve conhecimento da análise de Colomina e a ela reagiu, argumentando que havia virado seu rosto apenas para não aparecer na foto, pois o que deveria sobressair era a cadeira que, como bom móvel moderno e industrial, deveria poder ser usado por qualquer um. Ao refutar a interpretação da imagem, reafirmou um postulado central à própria idéia de mobiliário industrial: a produção em série e o usuário anônimo. Mais do que tomar partido entre a designer e sua analista, pretendo aqui propor outras possíveis leituras da fotografia de Charlotte Perriand em sua cadeira, recuperando seu papel no famoso ateliê da rue de Sévres, aludindo a trechos de sua autobiografia - plena, como não poderia deixar de ser, de ilusões biográficas - para pensar na dupla condição de gênero na elaboração e uso de objetos como a referida chaise-longue. Uma jovem deitada em uma cadeira de metal pode ser um pretexto para examinarmos fronteiras entre gênero - artes maiores e menores, por exemplo, artesanato e arte industrial - e gênero entendido como a contenciosa e negociada relação entre os sexos. 


\section{UMA FORMAÇÃO \\ EM TEMPOS DE TRANSIÇÃO}

Charlotte Perriand nasceu em Paris em 1903, filha de um alfaiate e uma modista e cresceu nas redondezas do Marché Saint-Honoré, onde seus pais residiam e trabalhavam, absorvendo o espaço social da alta-costura da perspectiva do pequeno artesão (MCLEOD, 2003: II). Em cada andar, recordou, trabalhava e morava um artesão: costureiro, chapeleiro, artífices que lidavam com plumas e couro, modistas e aprendizes. Seu pai cortava tecidos para a respeitada alfaiataria masculina Cumberland; sua mãe era especialista na confecção de coletes de piquê branco que eram usados por homens em recepções de gala. Essas evocações de Charlotte, aliadas a visitas ao mercado Les Halles para pedir as frutas não vendidas para fazer geléia (PERRIAND, I998: I2-I3) testemunham a presença de pequenos trabalhadores no centro de Paris, mesmo depois da reforma de Haussmann, e também testemunham um período de transição tanto da cidade e seus usos como desses pequenos ofícios. Nas últimas décadas do século xix, notou T.J. Clark, apesar de todas as alterações oriundas do "bota abaixo" que deu lugar aos elegantes bulevares, Paris ainda era uma cidade de trabalhadores, com mais homens ganhando a vida na indústria do que no comércio. Indústria no caso nos remete ao universo desses pequenos artesãos, a atividades feitas em forjas e oficinas com poucos trabalhadores, a gráficos, cortadores de vidro, alfaiates, cinzeladores, sapateiros etc. - a atividades tradicionais. Em suas palavras: o contexto da indústria era o quartier (CLARK, 2004: 95).

Ao mesmo tempo que a Paris haussmaniana preservava parte do espaço social das manufaturas, do pequeno comércio no centro, o consumo acentuado de bens de decoração e vestimenta reservava à mulher, desde os escritos dos irmãos Edmond e Jules de Goncourt, um papel de guardiã da graça, estilo e da beleza. No final do século xIx, oescritor e colecionador Octave Uzanne denunciava a simplicidade das femmes nouvelles como prejudicial para as artes decorativas francesas, que careciam da forma e do adorno femininos. Esse pioneiro em uma escrita que reintegrava artes e crafts preconizava uma aliança entre a graça feminina, o espaço interior e o refinamento artesanal, desde o século xvııI. Seu trabalho La femme à Paris, nos contemporaines, de 1894 , dizia que essa sobriedade minava um tipo de mulher parisiense orgânica, decorativa, e discutiu as implicações dessa nova postura às ordens urbana e doméstica. Ele celebrava a habilidade feminina de adornar seu próprio corpo e os espaços interiores aos quais ela naturalmente pertencia, mesclando mulheres decorativas e decoradoras, cujo modelo era a mulher aristocrática artesã, e delegando às esposas burguesas decorarem não apenas as paredes de suas casas, mas também cultivar luxo e o caráter artístico em suas "roupas de baixo". Uzanne e os Goncourts eram colecionadores ávidos da tradição artesanal feminina aristocrática e em sua cruzada contra a femme nouvelle, Uzanne lamentava que a loja de departamento tornasse impossível o caráter único da moda do século XviıI, mas as mulheres burguesas poderiam obter algo equivalente em distinção (sILverman, I989: 7I-2). 
Os pais e, em especial a mãe de Charlotte, situavam-se no pólo do pequeno produtor disso tudo, vivenciando a transformação entre a abundância de oficinas e pequenos ateliês do centro de Paris nas últimas décadas do século XIX e a movimentação ascendente dos grands magasins de nouveautés que arrebataram as mercadorias dos quartiers lançando-as nesses novos espaços que eram também lugares de entretenimento. Lojas de departamentos como Le Bon Marché, Grands Magasins du Louvre, Galleries Lafayette e Printemps, tornaram o ato de comprar menos pessoal: nelas qualquer burguês podia entrar, procurar pechinchas, distinguir o que comprar entre roupas que não foram cortadas sob medida. $\mathrm{O}$ que causou um forte efeito sobre a economia dos ateliês, que deixaram de folgar em feriados e dias santos, e passaram a segmentar as tarefas em estágios e a produzir com maior velocidade para atender os lojistas. Havia, claro, uma troca: enquanto a oficina se desintegrava, a costureira lidava diretamente com o capitalista e nesse contato ficava sabendo, o que não era de pouca relevância, o que seria a moda daquela estação (CLARK, 2004: IOI-3).

A filha, Charlotte, prosseguindo de maneira mais escolarizada no ramo de atividades dos pais, completou tal transição do ateliê para a grande loja. Deu também passos em outra transformação: sua mãe era uma mulher modesta, que trabalhava seu ofício à perfeição, mas não era necessariamente o modelo da femme nouvelle, arquétipo que a filha viria a perseguir e a nele se encaixar. Em I92I, com dezessete anos, Charlotte Perriand entrou - sem paixão pelos estudos, inconsciente quanto ao seu futuro (PERRIAND, I998: I6) - como bolsista no programa de quatro anos da Ecole de lUnion Centrale des Arts Decoratifs, uma escola feminina e de orientação feminista ${ }^{2}$ embora muitas das moças tivessem origem nas elites parisienses e a expectativa de um bom casamento (silverman, I998:III). Quando da passagem de Charlotte pela escola, sua direção estava a cargo de mulheres, exceto pelo diretor artístico, Henri Rapin (I873-1939). Mas essa aparente particularidade teve origem nas reformulações que a instituição sofreu por volta de 1890 , dentre as quais ecoava a visão desenvolvida em círculos oficiais, de que haveria um papel para a mulher na regeneração das artes

2 A Union Centrale des Arts Decoratifs foi fundada em 1864 como União Central das Belas Artes aplicadas à Indústria. Ficava na Place Royale (hoje Place des Vosges), bem no bairro de artesãos que era o Marais. Seus membros incluíam manufatureiros de papel de parede, tapetes, pianos, ourives etc. A mudança de nome veio com outras alterações em 1890. O termo "indústria" foi suprimido e os objetivos transformados: por volta de 1889, a idéia de vulgarizar o senso de beleza e democratizar a arte foi substituída por uma busca de purificação da beleza e aristocratização do artesanato, cf. SILVERMAN. aplicadas nacionais, e a partir de então a escola envolveu-se em campanhas para a liderança das mulheres na produção e consumo de um artesanato de luxo. Nesse momento, artistas como Eileen Grey, Sonia Delaunay, Hélène Henry, dentre outras ganhavam proeminência crescente no panorama da arte decorativa francesa (COSTA MEYER, 2003: 22).

Charlotte não teve uma passagem brilhante ou destacada na escola, e sim um percurso errático com aulas cabuladas para passeios no Jardim de Luxemburgo, o que criou problemas com sua condição de bolsista e uma quase expulsão no segundo ano. Decidida a trabalhar com a mãe e por esta impedida, não teve outra saída senão apresentar novos desenhos ao professor Rapin. Quando a escola se mudou para as dependências do Musée des Arts Décoratifs no Louvre, ela passou a frequentar as aulas dos pintores Berbard Boutet de Montvel e de Andrè Lhote. E passou a complementar sua formação, o que 
foi mais decisivo, nas aulas vespertinas de Maurice Dufrène ${ }^{3}$, o presidente do Salon des Artistes Décorateurs, responsável pelo desenho de mobiliário das Galerias Lafayette. Foi a formação complementar que reintegrou Charlotte à

3 Maurice Dufrène (1876-1855) freqüentou e École Nationale des Arts Décoratifs e foi, em 1902, um dos fundadores do Salon des Arts Décoratifs. Em 1921 assumiu a direção do ateliê La Maitrise, das Galleries Lafayette.

4 A Exposition Internationale des Arts Décoratifs et Industriels Modernes, muitas vezes denominada apenas Art Déco teve lugar em Paris de Abril a Outubro de 1925 e tinha como um de seus objetivos promover a indústria francesa que perdia seu protagonismo na Europa posterior à Primeira Guerra.

5 Há uma homologia entre esse olhar que não se fixa nos pavilhões de proposta modernista e a atitude de Lucio Costa em 1929, que praticamente ignorou a passagem de Le Corbusier no Rio de Janeiro. De qualquer modo, devemos nos perguntar até que ponto o impacto dos dois pavilhões modernistas - o soviético de Konstantin Melnikov e o de Le Corbusier - não é uma construção posterior ao evento, ditada mais pela bibliografia defensora do Movimento Moderno do que pela visibilidade nos mesmos na ocasião.

6 Paul Follot foi o diretor artístico do estúdio Pomone, $o$ ateliê de arte dos armazéns Bon Marché entre 1923 e 1928. Produzia mobiliário e objetos em séries limitadas, usando materiais como madeira machetada, marfim e bronze. escola - "eu não era mais vista como marginal", recordou (PERRIAND, I998: I9) - e ela foi uma das escolhidas para a exposição de artes decorativas de $1925^{4}$, apresentando três trabalhos na vitrine de sua escola: um conjunto de nove painéis para uma sala de música representando as nove musas; uma grade de ferro forjado; e uma capa de couro para o livro Eupalinos, de Paul Valéry. E para o Pavilhão de Dufrène para as Galleries Lafayette, coordenado por Dufrène, ela desenhou um suporte para quadros, que depois seria produzido e comercializado. Nessa mostra, sua atenção foi para os pavilhões de prestígio e das grandes lojas de departamento e não para os da União Soviética ou do Esprit Nouveau, cujos protagonistas fariam parte das suas futuras redes de trabalho e sociabilidade ${ }^{5}$.

Uma vez formada, Charlotte recebeu de Dufrène e Rapin o conselho de que buscasse a todo custo expor - afinal, ninguém a conhecia. Ao apoio de seus mestres veio a juntar-se o suporte de Henri Clouzot (1865-194I), diretor do Musée Galliéra, figura importante que congregava os desenhistas de mobiliário na Paris desses anos. $\mathrm{O}$ aconselhamento profissional nesse momento assinala $\mathrm{o}$ perfil distinto de suas colegas de curso, evidenciando que ela não havia freqüentado o curso por diletantismo ou à espera de um casamento, mas em busca de uma qualificação para o trabalho. E ela se dedicou, com ajuda financeira de seus pais e marceneiros indicados por Dufrène a projetar o canto de uma sala, Coin de Salon, sua primeira obra em mobiliário, exibida no salão anual da Société des Artistes Décorateurs, em Paris. A perspectiva de Dufrène, em plena consonância com os planos das lojas Lafayette e Printemps, era criar um mobiliário para o "francês médio" e para o espaço reduzido dos apartamentos parisienses. A recepção ao trabatho de Perriand, ainda na linguagem observada na grande exposição do ano anterior, foi ambivalente: de um lado sua estante-escrivaninha foi elogiada, sua presença feminina foi notada e de outro o inusitado de se juntar madeira e vidro foi também observado, assim como o desenho limpo que contrastava com as obras de seus mestres Maurice Dufrène e Paul Follot ${ }^{6}$, ainda que não se saiba se uma certa economia de recursos consistia então em uma escolha ou a um ajuste às dificuldades econômicas de uma obra financiada pela família (COSTA MEYer, 2003: 25). Nesse mesmo ano, a poltrona do conjunto foi exibida no Musée Galliera e sua amiga Marianne Clouzot, filha do diretor do museu desenhou os tecidos usados no móvel (RÜEGG, 2004: IO).

O conjunto Coin de Salon foi adquirido por um inglês, comerciante de tecidos, amigo da família, Percy Scholenfield, com quem ela se casou no final de 1926. Se este texto dependesse apenas das memórias de Perriand, pouco 
saberíamos desse enlace, apenas que ele era inglês, protestante, que ela se casou contra a vontade do pai e vestida de vermelho: "Pensado da perspectiva de agora, eu penso que o casamento naquela época era o único caminho possível para que a crisálida virasse borboleta. E a borboleta, ela voa." Charlotte encontrou no marido seu mecenas: Scholenfield patrocinou sua participação nos próximos salões, ao mesmo tempo que ofereceu atividades que poderiam aprimorar sua atuação: matemática e arquitetura para superar sua defasagem cul-

7 "Em y reflechissant aujourd'hui, jê pense que Le mariage à cette époque était le seul passage possible pour que la chrysalide devint papillon. Et um papillon, ça vole." (PERRIAND, 1998: 22). tural, e também de condução de automóveis e de inglês (BARSAC, 2005: 24). As transformações propiciadas pelo casamento são de ordem diversa: ela deixou a margem direita do Sena e seus ofícios artesanais, mudou-se para o Quartier Latin, iniciou-se na literatura inglesa, no jazz, cortou os cabelos à la garçonne e passou a admirar Josephine Baker. Passou a encarnar a nouvelle femme, que na geração de sua mãe era banida em todos os discursos como sinônimo da degenerescência da França. Desenhou e mandou executar um colar de bolotas de metal como se essa peça, de um modo um tanto metonímico, contivesse toda mudança e modernidade que sua trajetória futura parecia anunciar. Seu comportamento não deve ser lido na chave da rebeldia individual, menos ainda pelo charme e graça impresso na recordação que reconstrói sua biografia. As narrativas ficcionais e os atores sociais que encarnavam a nova mulher francesa só poderiam ter lugar numa cultura de massa e de imprensa, em uma cultura urbana teatralizada, espetacularizada que borrasse a distinção entre fantasia e realidade e permitisse que o leitor passasse da tradução da ficção para sua vida cotidiana. Essa era a Paris fin-de-siècle, cuja renovação urbana e crise econômica transformaram a face da cidade permitindo a emergência de uma cultura de consumo, de imprensa de massa, de uma rua espetacular pelos bulevares haussmanianos. Foi o mercado dos sonhos de massa que deu lugar a uma geração de femme nouvelle, conectada não apenas com a Terceira República, mas sobretudo com a mercantilização da cultura urbana francesa. (ROBERTs, 2002: 7).

$\mathrm{Na}$ França posterior à Primeira Guerra, as grandes lojas de departamento instituíram seus próprios estúdios de design de mobiliário, mudança vinculada tanto a essa passagem de uma economia de guerra para um consumo de massas. Ao mesmo tempo que os papéis de mulher e a mãe eram ligadas discursivamente à segurança nacional, no campo artístico a idéia de um "retorno à ordem" casava bem com a proposta de um possível fordismo na vida doméstica que chegava dos Estados Unidos e da Alemanha. Do outro lado do rio Sena, a banda boêmia em que viviam artistas e escritores e sobretudo mulheres artistas como Gertrude Stein, e com outros recursos materiais e simbólicos, Charlotte pôde fazer de seu apartamento de mulher casada um laboratório de inventividade, o que em seus móveis se revela pela substituição da madeira pelo metal. Em contato com os serralheiros do Marais, recomendados por Dufrène, ela pretendia aplicar aos móveis as técnicas de carroceria de automóveis - lembrando o fascínio que o automóvel exercia então, especialmente em tudo o que significava simbolicamente (e Charlotte aprendeu a dirigir com seu marido). Nessa nova situação, ela apresentou ao Salon des Artists Décorateurs um projeto chamado Bar sous le Toit, com forte 
uso de cobre niquelado. No mesmo ano de 1927, começou a conceber sua sala de jantar, com cadeiras pivotantes em couro e metal tubular. Seu apartamento, visitado por um crítico, Marcel Zahar, teve a sala de jantar descrita como um espaço que seduz por sua coqueteria (BENTON, 2005: I2). Bar sous le toit. projetado em situação de maior autonomia em relação a seus mestres, foi a obra de transição em sua carreira que se iniciava. Segundo Costa Meyer, foi o momento em que ela agregou uma idéia de espaço exterior, de rua ao espaço de um apartamento e abandonou noções de genius loci. Podemos argumentar que, mais do que isso, nesse momento ela interpelou a noção de domesticidade burguesa tão propalada na exposição de 1925 , nos trabalhos dos estúdios das grandes lojas, na imprensa especializada, uma domesticidade que dividia a casa por gênero, espaços masculinos e femininos - afinal, uma jovem senhora projetou um bar, lugar masculino por excelência.

Se o bar sob o teto, e o teto era de uma mansarda parisiense e não de um apartamento luxuoso, começou a delinear uma ruptura em relação a seus mestres - mas é preciso lembrar que Dufrène era mais “moderno" do que Rapin e Follot - em 1927 ela também esboçou outras articulações em termos de redes e grupos de trabalho. Sob o impacto da exposição Die Wohnung em Stuttgart, um grupo formado por René Herbst (I89I-I982), Georges Djo-Bourgeois (I898-I937) e Charlotte se autodenominaram unidade de choque (unité de choc) e apresentaram um trabalho conjunto, o interior de um apartamento no Salon des Artistes Décorateurs de 1927. O bar de sua casa, exibido no Salon d'automne, final de 1927 foi bem recebido pela imprensa e é nesse momento que ela encontrou Le Corbusier. Ela já usava metal, já imaginava ambientes despojados de excessos ornamentais, já articulava redes de artistas modernos, enfim, já era moderna e já experimentara algum sucesso antes de conhecer o arquiteto que então já havia provocado a cidade com suas casas, escritos e planos de cidade.

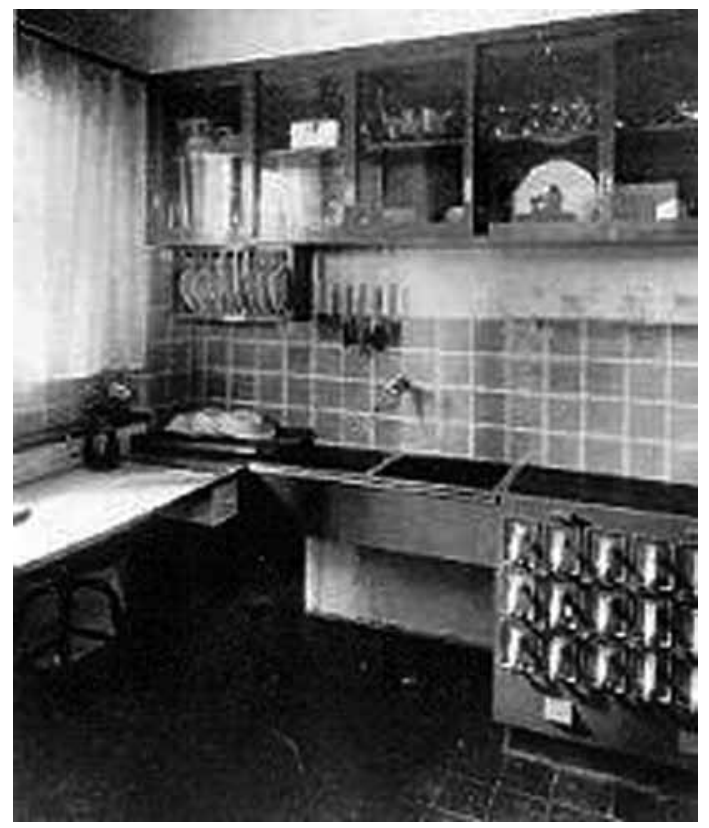


Aparentemente, foi a leitura de Vers une Architecture e L'art décoratif d'aujourd'bui que levou Charlotte a pedir trabalho para Le Corbusier. "Aqui não bordamos almofadas", foi a resposta que ouviu do já conhecido arquiteto suíço. Le Corbusier e seu primo e braço-direito Pierre Jeanneret, contudo, visitaram a ambientação Bar sous le toit e a convidaram a juntar-se a eles e outros companheiros no ateliê que chefiava, não sem a "não-benção" de Dufrène que predicou que ali ela "secaria por dentro". As falas de Corbusier e Dufrène, profissionais situados em pólos opostos no campo da arte decorativa de então, indicam diversos níveis de contenciosos. De um lado, conhecendo o ensino de artes decorativas - em que pese toda a misoginia de sua fala - Le Corbusier talvez não pudesse esperar muito mais de uma jovem com tal formação. Ainda assim, é uma fala de não-investidura, de desclassificação, desqualificação. Contudo, não foi certamente para defendê-la dessa postura que Dufrène não apostou em seu futuro no novo ateliê, e sim para explicitar as dificuldades que viriam: não necessariamente por ela ser mulher, mas sobretudo por tratar-se de um ateliê que era quase uma corporação de ofício, onde jovens de várias origens abrigavam-se à sombra daquele que consideravam um mestre. De qualquer modo, Le Corbusier não foi apenas seduzido pelo mobiliário que viu: notou que ela tinha boa formação - aluna de Dufrène e Rapin - e que aceitaria trabalhar como voluntária (RÜEGG, 2004: I5).

Ao que tudo indica a visita frustrada da jovem Perriand, então com 24 anos, ao ateliê de Corbusier ocorreu alguns dias após o encerramento da exposição de Stuttgart ${ }^{8}$. Nessa mostra de habitações, a cozinha foi o centro das atenções, com as regras gerais definidas por uma Associação de Donas de Casa de Stuttgart e pelo livro Der neue Haushaut, livro de 1926 da feminista Erna Meyer sobre a "nova casa" que vendeu vinte e nove edições em dois anos, e que vinha ilustrado com casas construídas por arquitetos ligados ao Neues Bauen e com equipamento projetado pela Bauhaus. A casa apresentada pelo arquiteto J.J.P. Oud era um exemplo desse novo ideal de casa eficiente. Por outro lado, os interiores das casas de Le Corbusier, desenhados por Alfred Roth sem qualquer ajuda do mestre, foram mal recebidos, considerados mal

8 Exposição dirigida por Mies van der Rohe que consistia em trinta e uma edificações profetadas por dezessete arquitetos, incluindo blocos de apartamentos do próprio Mies, de J.J.P. Oud e de Mart Stam, e diversas casas, o que incluía duas de Le Corbusier e Pierre Jeanneret. Segundo Mary McLeod (2003:37), os interiores das casas alemãs eram elegantes, enquanto Le Corbusier não dava conta de equipar suas casas à altura de seus projetos arquitetônicos. Nesse caso, no último momento, seu parceiro Alfred Roth desistiu de esperar os projeto de equipamento que não chegava e improvisou, com um resultado que contrastava muito com o interior do apartamento de Mies, projetado em parceria com Lilly Reich. Le Corbusier foi severamente criticado pelos alemães. acabados e aquém do arrojo da proposta arquitetônica.

No ateliê, sem remuneração e com o status de associada para o equipamento interior, Charlotte pôde oferecer expertise naquilo que faltava ao grupo de Le Corbusier: a desprezada arte decorativa, e ela colaborou com os interiores da Villa La Roche e da Villa Church. Embora já estivesse no ateliê, exibiu sua sala de jantar, a mesma elaborada em seu apartamento-laboratório, em Maio de 1928 no Salon des artistes décorateurs com sucesso e presença na imprensa. Suas cadeiras pivotantes começaram a fazer parte dos projetos em grupo, ou seja, seus móveis em metal tubular tornaram-se protótipos para o mobiliário 
do ateliê. Como grupo, o trio Corbusier-Jeanneret-Perriand apresentou uma proposta para o salão de 1929 e pela primeira vez, ela recebeu uma recusa no mesmo espaço onde, um ano antes, havia exposto algo bastante semelhante sendo bem recebida. Ao lado de mais dezessete membros, ela retirou sua afiliação à sociedade e participou da fundação da Union des Artistes Modernes (UAM).

No meio dessa movimentação ela projetou a chaise-longue na qual se fez fotografar. Trata-se de uma espreguiçadeira - ou seja, não é uma cadeira de trabalho - com estrutura metálica e vedação em tecido e/ou couro, que possibilita várias posições a serem fixadas pelo peso do corpo de quem a ocupa.Tem como precedentes as cadeiras de balanço em madeira e palhinha patenteadas por Thonet e uma cadeira de repouso, para fins terapêuticos conhecida como Surrepos, assinada por alguém identificado como Dr. Pascaud, e uma cadeira de duquesa, móvel de descanso feminino do século anterior. Curiosamente, em Precisões, Le Corbusier evocou qualidades masculinas para a chaise-longue, descrita como uma "máquina de sentar" feita de tubos de bicicleta, e publicou a mesma em suas obras completas usando as icônicas fotos que mostram Charlotte em repouso e ocultando seu rosto.

Enquanto Le Corbusier proferia suas conhecidas palestras em Buenos Aires e Rio de Janeiro, Charlotte encenou e Pierre Jeanneret fotografou. Há três versões dessa imagem, que depois foi utilizada em diversas fotocolagens para mostrar ambientes modernos. Charlotte sempre explicou sua posição na cadeira como uma sugestão de qualquer usuário possível, sem rosto, mas como observou Mary McLeod, com suas pernas estendidas e à mostra, a roupa junto ao corpo, há algo de coquete na imagem. Em suas palavras, a "foto, como a cadeira, tem um charme sedutor, que revela a presumida neutralidade da estética da máquina"9 . Eu prestaria ainda mais atenção

9 MCLEOD, Mary. (2003) ao termo "coquete", lembrando que o trabalho da designer foi assim recebido já no início da carreira e que foram estas as palavras de Le Corbusier ao ver pela primeira vez algumas cadeiras prontas: "ils sont coquets".

Em um instigante ensaio que Georg Simmel publicou em 1923 - "Die Koketterie” - em seu livro Philosophische Kultur esse termo é levado a sério. Simmel parte da formulação platônica segundo a qual o amor consiste num jogo entre ser e não ser, para definir a coqueteria como um exemplo de jogo e sociabilidade, de relação, uma arte entre o aproximar-se e o afastar-se, dar e negar - arte na qual os protagonistas jogam uns com os outros. Nesse jogo, a coqueteria remete ao olhar de soslaio, à cabeça um pouco reclinada. A descrição de Simmel, mais complexa do que aqui nos interessa, poderia ser a mais perfeita legenda à imagem de Charlotte em sua cadeira.

Charlotte ao deitar em sua cadeira, fazendo-se ali eternizar, não se afirmou por seu marido, sua prole ou sua origem social. Afirmou-se por sua obra: uma cadeira de repouso, pequena como sua autora. Talvez fosse impossível no contexto encarar a câmera como a dizer "é minha", mas é visível que ela assinou ao mesmo tempo texto e objeto ao publicar esta imagem no artigo "Wood or metal?"(madeira ou metal?), manifesto que em termos lexicais e de 
conteúdo não difere muito de outros publicados no mesmo período, mas que permaneceu, assim como o nome de Charlotte Perriand, um tanto esmaecido até sua recente "redescoberta".

Sentar-se, lembra a historiadora Vania Carvalho, mais do que mera prática corriqueira, é um "gesto socialmente significativo e, por isso mesmo, sexualmente ativo". E se uma casa é parte de uma objetivação da "ordem das coisas", com suas partes todas "sexuadas", o corpo é não apenas realidade sexuada como "depositário de princípios de visão e de divisão sexualizantes." Repousando, com os olhos fechados, ela praticava - prestes a se divorciar, iniciando seu flerte com a esquerda francesa - a resistência silenciosa que, segundo Diane Crane,as mulheres realizam com sua vestimenta e que, no caso que aqui nos interessa, transportamos para uma possível análise dessa relação entre corpo, objeto e autoria evidenciada pela foto em questão.

Pouco depois ela deixaria o ateliê, a pedido do próprio Le Corbusier e suas carreiras, que no segundo pós-guerra viriam a se juntar novamente - Charlotte projetou os interiores de diversos projetos, inclusive a Unidade de Habitação de Marselha e a Casa do Brasil, na cidade universitária - se afastam espacial e simbolicamente. Em plena proximidade ideológica com a esquerda francesa e o front populaire, Charlotte foi convidada a passar uma temporada, que com a guerra se revelou longa, no Japão e posteriormente na Indochina. No Japão em I942, ela redesenhou sua espreguiçadeira em bambu e palha de arroz e a mostrou singelamente, sem precisar tomar posse com seu corpo, uma vez que estava longe dos contenciosos que a fotografia pode permitir entrever. Le Corbusier, por sua vez, passou em I942 a colaborar com o governo de Vichy, enquanto seu primo Pierre Jeanneret se juntava à resistência francesa. Vichy sob as ordens de Pétain significou um retrocesso em relação às aspirações da tal nouvelle fem$m e^{10}$, antes admirada por Corbu que assim a descreveu em

Io Ver o belo livro de Muel-Dreyfus, Vichy et leternel feminin, sobre o trabalho ideológico em relação às mulheres e seu lugar na sociedade francesa. Precisões, como se falasse de sua colaboradora:

A mulher nos precede. Ela realizou a reforma de seu traje. Ela encontrava-se num impasse: seguir a moda e então renunciar à contribuição das técnicas modernas, à vida moderna. Renunciar ao esporte e, problema mais material, não poder aceitar empregos que lhe permitiriam ter uma participação fecunda na atividade contemporânea e ganhar sua vida. Seguir a moda: ela não podia pensar em guiar; não podia nem o metrô, nem o ônibus, não podia sequer agir com desenvoltura em seu escritório ou na loja. Para poder realizar a construção cotidiana de sua toalete - pentear-se, calçar o sapato, abotoar o vestido - ela não tinha mais tempo para dormir. Então a mulher cortou seus cabelos, suas saias e suas mangas. Agora está com a cabeça descoberta, os braços de fora e as pernas livres. Veste-se em cinco minutos. E é bela, seduz com o encanto de suas graças, das quais os modistas resolveram tirar partido" (LE CORBUSIER, 2004 [I93O]: II2).

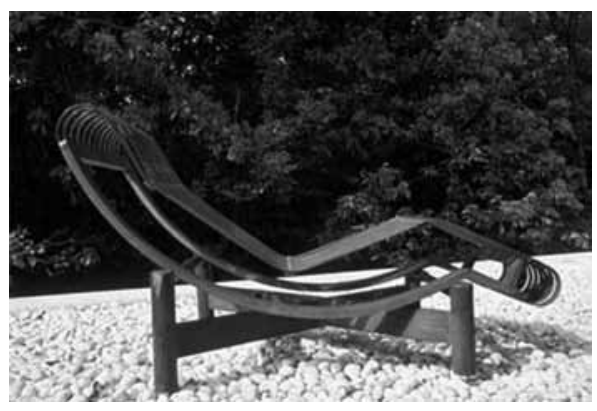


Um doce, sutil e possivelmente pouco consciente manifesto: se a cadeira tornou-se indissociável da imagem de sua autora nela repousada, ela foi registrada em nome do trio Corbusier-Jeanneret-Perriand, para hoje ser conhecida apenas como LC 9. De certo modo, como as relações de gênero (homem e mulher, arquitetura e design, arte e decoração, entre outras) já estavam postas em questão, podemos ler essa foto sem as amarras da sujeição, como quis Colomina, mas tampouco sem a singeleza do gesto pretendido por Charlotte.

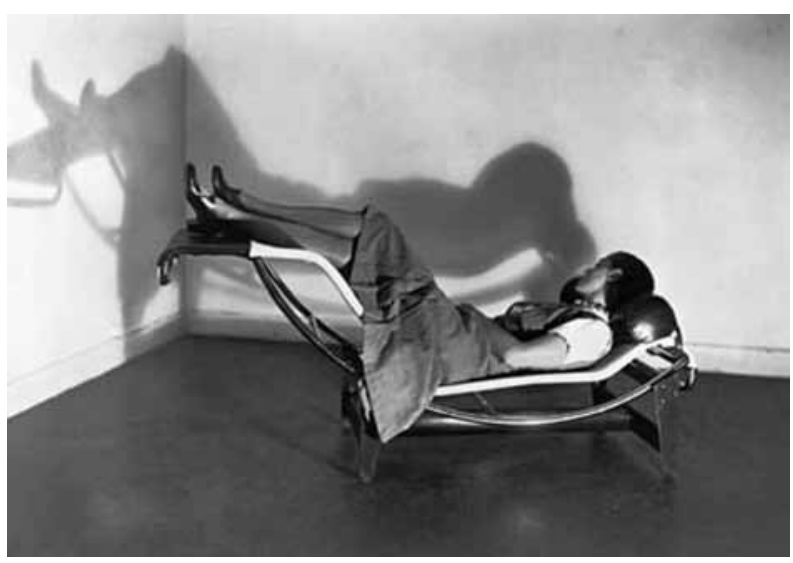

Se não conseguimos observar a participação feminina no Movimento Moderno em arquitetura sem marcas de sujeição e auto-sujeição, tampouco temos apenas essa possibilidade de leitura. Perriand, como as mulheres da Bauhaus e outras designers do seu tempo, construiu sua carreira nas brechas estipuladas por uma dominação masculina no campo, mas não sem deixar as marcas de uma sutil revolução simbólica. As casas que hoje conhecemos tem aspectos pensados de dentro pra fora, caraterística marcante do trabalho feminino nessa área. Designer que em diversos momentos tentou se tornar arquiteta, Perriand legou transformações importantes no espaço doméstico e na produção de seus parceiros de trabalho, como Corbusier e posteriormente Jean Prouvé.

A delicada foto de 1929 pode ser interpretada como uma potente reivindicação de visibilidade, nome, existência e autoria, ainda que a hexis corporal indique uma resistência e um clamor que só podia se apresentar desse modo: um pouco enviesado, quase de soslaio.

\section{Bibliografia}

BARSAC, Jacques (2005). Charlotte Perriand, un art d'habiter. Paris, Norma Éditions.

-

BAXANDALL, Michael (2006). Padrões de intenção. São Paulo, Companhia das Letras.

-

BENTON, Tim (2005)."Charlotte Perriand: lês années Le Corbusier". Centre National d'Art et de Culture Georges Pompidou, Charlotte Perriand. Paris, Éditiond du Centre Pompidou.

-

BOURDIEU, Pierre. A dominação masculina. Rio de Janeiro: Bertrand Brasil, 1999.

-

CARVALHO, Vania C.(2008). Gênero e artefato: 0 sistema doméstico na perspectiva da cultura material São Paulo, 1870-1920. São Paulo, EDUSP.

-

CLARK. T.J. (2004). A pintura da vida moderna. Paris na arte de Manet e de seus seguidores. São Paulo, Companhia das Letras.

-

COLOMINA, Beatriz (1992). "The split wall: domestic voyeurism".
COLOMINA, B. (ed). Sexuality and space. New York, Princeton Architectural Press.

-

COLOMINA, Beatriz (2000). Privacy and publicity. Modern architecture as mass media. Woburn, Massachussets, Massachussets Institute of Technology.

-

COSTA MEYER, Esther. (2003). "Simulated domesticities: Perriand before Le Corbusier". McLEOD, Mary (org). Charlotte Perriand: an art of living. New York, Harry Abrams Inc. Publishers, pp 22-35.

$-$

CRANE, Diana. (2006). A moda e seu papel social. São Paulo, Editora Senac.

LE CORBUSIER (2004 [1930]). Precisões sobre um estado presente da arquitetura e do urbanismo. São Paulo, Cosac \& Naify.

\section{-}

MCLEOD, Mary (2003). "New designs for living: domestic equipment of Charlotte Perriand, Le Corbusier and Pierre Jeanneret, 1928-29". McLEOD, Mary (org). Charlotte Perriand: an art of living. New York, Harry Abrams Inc. Publishers, pp. 36-67.
MUEL-DREYFUS, Francine (1996). Vichy et l'éternel feminine. Paris, Seuil.

PERRIAND, Charlotte (1998). Une vie de création. Paris, Odile Jacob.

POLLOCK, Griselda (2003). Vision and Difference. Feminism, femininity and the histories of art. London and New York, Routledge.

-

OBERTS, Mary Louise. (2002) Disruptive Acts. The New Women in Fin-de-Siècle France. Chicago, University of Chicago Press.

RUEGG, Arthur. Charlotte Perriand Livre de Bord. Basel/Boston/Berlin, Birkhäuser publications for Architecture.

-

SILVERMAN. Debora L. (1992). Art nouveau in fin-de siècle France: politics, psychology and style. Berkeley, University of California Press. 